\title{
EVALUATION OF SILENT MYOCARDIAL ISCHEMIA IN ASYMPTOMATIC TYPE 2 DIABETES MELLITUS PATIENTS BY TREAD MILL TEST IN TERTIARY CARE CENTER IN SOUTH INDIA
}

\author{
Malepati Sai Sarath Reddy¹, Uma Mylandlahalli Anandkumar², Srinivasa Rao 3 \\ 1Postgraduate Resident, Department of General Medicine, PES Institute of Medical Sciences, Kuppam, Chittoor, Andhra Pradesh, India. \\ ${ }^{2}$ Associate Professor, Department of General Medicine, PES Institute of Medical Sciences, Kuppam, Chittoor, Andhra Pradesh, India. \\ 3 Professor and HOD, Department of General Medicine, PES Institute of Medical Sciences, Kuppam, Chittoor, Andhra Pradesh, India.

\section{ABSTRACT}

\section{BACKGROUND} \\ Diabetes is an important and treatable risk factor for Coronary Artery Disease (CAD). Routine electrocardiography (ECG) and \\ cardiac imaging cannot diagnose these patients. Hence the present study was done to estimate the prevalence of silent myocardial \\ ischemia (SMI) in asymptomatic type 2 diabetic patients by Tread Mill Test (TMT). Assess the role of Tread Mill Test (TMT) in \\ detecting the prevalence of silent myocardial ischemia (SMI) in type 2 diabetic patients.
}

\section{MATERIALS AND METHODS}

Asymptomatic diabetes mellitus (DM) patients aged 30 to 60 years with a normal resting ECG and echocardiography (ECHO) were included in the study. A detailed clinical history, a thorough medical examination and relevant biochemical parameters were analysed in all study subjects. The treadmill test was performed on each participant according to the Bruce protocol.

\section{RESULTS}

In this study, the prevalence of silent myocardial ischaemia in asymptomatic DM patients was $22.2 \%$, as shown by positive TMT test. Among these study subjects, 10 (22.7\%) were males and 6 (21.4\%) were females. Among the risk factors, association of age, duration of diabetes, HbA1c levels were correlated with TMT positivity for inducible ischemia.

\section{CONCLUSION}

The silent nature of CAD in many diabetes patients makes remain undiagnosed for long periods of time. Hence there is a need for screening of diabetes patients for MI. In a rural setup where there are limited resources, TMT can be used as a screening tool for diagnosing SMI. Elderly diabetics with longer duration of diabetes and poor glycemic control had higher prevalence of inducible ischemia. Good glycemic control had a protective effect against development CAD.

\section{KEY WORDS}

Diabetes Mellitus, Silent Myocardial Ischemia, Tread Mill Test

HOW TO CITE THIS ARTICLE: Reddy MSS, Anandkumar UM, Rao S. Evaluation of silent myocardial ischemia in asymptomatic type 2 diabetes mellitus patients by tread mill test in tertiary care center in South India. J. Evolution Med. Dent. Sci. 2019;8(10):740-744, DOI: $10.14260 /$ jemds/2019/162

\section{BACKGROUND}

India has the dubious distinction of being considered the diabetes capital of the world because of increasing diabetic population. The proportional mortality rate in the year 2012 was $2 \%$ due to diabetes in India. ${ }^{1}$ Diabetes is an important and treatable risk factor for Coronary Artery Disease (CAD), blindness, renal failure, and limb amputation. ${ }^{2}$ Mortality in diabetes due to coronary events is twice in men and four times in women compared to their non-diabetic controls. ${ }^{3}$ CAD has a prevalence of $6.4 \%$ and $2.5 \%$ in urban and rural areas respectively. In persons with diabetes, myocardial ischemia (MI) often progresses silently and causes fatal cardiac events. ${ }^{4}$

'Financial or Other Competing Interest': None.

Submission 11-01-2019, Peer Review 20-02-2019,

Acceptance 26-02-2019, Published 11-03-2019.

Corresponding Author:

Dr. Uma Mylandlahalli Anandkumar,

Associate Professor,

Department of General Medicine,

No. 105, Hill View Apartment, PESIMSR Campus,

PES Institute of Medical Sciences,

Kuppam-517425, Chittoor Dist.,

Andhra Pradesh, India.

E-mail: uma.m.anand@gmail.com

DOI: $10.14260 /$ jemds $/ 2019 / 162$ autonomic neuropathy. ${ }^{5}$ This delays the diagnosis during the initial stages. Hence the early diagnosis of asymptomatic CAD is useful in preventing these fatal events. Routine electrocardiography (ECG) and cardiac imaging cannot diagnose these patients. American Diabetic Association recommends the use of a stress ECG test for diagnosing silent ischemia. ${ }^{6}$ Treadmill Test (TMT) is a safe, non-invasive, cost effective and easily available tool for diagnosis of Silent Myocardial Ischemia (SMI). Hence the present study was done to measure the prevalence of silent myocardial ischemia by TMT in asymptomatic type $2 \mathrm{DM}$ patients in a rural tertiary care hospital.

\section{MATERIALS AND METHODS}

The present study was a hospital based cross sectional study conducted at PES Institute of Medical Sciences (PESIMSR) Kuppam, Andhra Pradesh. The study was conducted over a period of 12 months after ethical committee clearance. Asymptomatic Diabetes mellitus patients aged 30 to 60 years with a normal resting electrocardiogram (ECG) and echocardiography (ECHO) were included in the study. A total of 72 subjects who fulfilled the inclusion criteria were selected for the study by purposive sampling. Patients unable to do TMT or not willing to participate in the study were excluded. 
After counselling, consenting patients with type 2 diabetes mellitus were included in the study. Collection of sociodemographic data detailed clinical history, and a thorough medical examination were done on all study subjects. Resting ECG and echocardiography was done. The Treadmill test was performed on each participant according to the Bruce protocol ${ }^{7}$ on a motor driven machine with a treadmill. The subjects were asked to stop beta blockers, calcium channel blockers 72 hours before and to stop smoking for one day before the scheduled TMT study. All the subjects were made to walk up to 9 minutes ( $3^{\text {rd }}$ stage of Bruce protocol) and asked to rest in the supine position for 6 minutes. They were followed with pulse rate, blood pressure, ECG done every 3 minutes during the procedure and for every minute during the recovery period.

The TMT was considered satisfactory when at least $85 \%$ of the age-determined heart rate (220 minus age) was reached. The exercise test was stopped, if there was chest pain, dyspnoea, near syncope, hypotension, exhaustion or significant arrhythmia. The procedure was terminated within 60 seconds if any ischemic event was detected.

The exercise ECG was defined 'positive' for inducible ischemia if a horizontal or down-sloping ST-segment depression of $1 \mathrm{~mm}$ or more occurred at 0.08 second after J point, in 2 or more contiguous leads, during peak exercise and persisting for at least 6 minutes into the recovery phase. The data were entered into MS Excel 2007 version and analysed using Epi Info 7.1. The categorical variables were analysed by using percentages, and the continuous variables were analysed by calculating the mean \pm standard deviation. For inferential analysis, 'chi' square test was applied and pvalue $<0.05$ was considered as statistically significant.

\section{RESULTS}

The present study was conducted on 72 type 2 diabetes patients. The mean age of study participants was $50.5 \pm 9.4$ years and among them, maximum age groups of distribution were $40-49$ years $(n=24,33 \%)$ and $50-59$ years $(n=24,33 \%)$. (Table 1). In the present study, the majority of subjects (72.2\%) were on oral antidiabetic drugs, of the 72 study subjects, $19(26.4 \%)$ were hypertensive and 53(73.6\%) were normotensives. Diabetic retinopathy was found in $32(44.4 \%)$ of study subjects and $17(23.6 \%)$ had autonomic neuropathy. On assessment of BMI $57 \%$ of the subjects were overweight $(12.5 \%)$ and obese $(44.5 \%)$. (Table 2$)$. In the present study 22 subjects had HbA1c of $<7$. The mean values of various biochemical parameters studied are depicted in table 3 . When asymptomatic study subjects were tested for inducible ischemia by TMT, it was found positive in $16(22.2 \%)$ of study subjects. The prevalence of silent myocardial ischemia in this study was $22.2 \%$. When age was taken into consideration, TMT was positive in $66.7 \%$ of patients above the age of 60 years compared to $10.5 \%$ in patients aged less than 60 . TMT was highly significant for inducible ischemia in patients who had HbA1c $>7$, duration of diabetes more than 10 years and patients aged more than 60 years. (Table 4). In the present study Fasting blood glucose (FBS), Post prandial blood glucose (PPBS), triglycerides, low density lipoprotein (LDL) and high-density lipoprotein (HDL) cholesterol did not have any significant association with inducible ischemia.

\begin{tabular}{|c|c|c|}
\hline Parameters & Frequency & Percentage \\
\hline \multicolumn{3}{|c|}{ Age (in Years) } \\
\hline $30-39$ & 9 & 12.5 \\
\hline $40-49$ & 24 & 33.3 \\
\hline $50-59$ & 24 & 33.3 \\
\hline$\geq 60$ & 15 & 20.9 \\
\hline \multicolumn{3}{|c|}{ Gender } \\
\hline Male & 44 & 61.1 \\
\hline Female & 28 & 38.9 \\
\hline \multicolumn{3}{|c|}{ Family History of Diabetes Mellitus (DM) } \\
\hline Yes & 29 & 40.2 \\
\hline No & 43 & 59.8 \\
\hline \multicolumn{3}{|c|}{ Duration of Diabetes (in Years) } \\
\hline$<5$ Years & 10 & 13.9 \\
\hline 5-10 Years & 40 & 55.54 \\
\hline$>10$ Years & 22 & 30.56 \\
\hline \multicolumn{3}{|c|}{ Family History of IHD } \\
\hline Present & 11 & 15.3 \\
\hline Absent & 61 & 84.7 \\
\hline \multicolumn{3}{|c|}{ Hypertension } \\
\hline Yes & 19 & 26.4 \\
\hline No & 53 & 73.6 \\
\hline \multicolumn{3}{|c|}{ Personal Habits } \\
\hline Smoking & 12 & 16.7 \\
\hline Alcoholism & 8 & 11.1 \\
\hline $\begin{array}{l}\text { Smoking \& } \\
\text { Alcoholism }\end{array}$ & 6 & 8.3 \\
\hline None & 46 & 63.9 \\
\hline \multicolumn{3}{|c|}{ Treatment History } \\
\hline $\begin{array}{c}\text { Oral Antidiabetic } \\
\text { Drugs }\end{array}$ & 52 & 72.2 \\
\hline Insulin & 20 & 27.8 \\
\hline
\end{tabular}

\begin{tabular}{|c|c|c|}
\hline BMI $\left(\mathrm{Kg} / \mathbf{M}^{2}\right)$ & Frequency & Percentage \\
\hline Underweight $(<18.5)$ & 1 & 1.4 \\
\hline Normal (18.5-22.9) & 30 & 41.6 \\
\hline Overweight (23-24.9) & 9 & 12.5 \\
\hline Obese $(\geq 25)$ & 32 & 44.5 \\
\hline Total & 72 & 100 \\
\hline
\end{tabular}

\begin{tabular}{|c|c|}
\hline Variable & Mean \pm SD \\
\hline FBS & $140.9 \pm 41.8 \mathrm{mg} / \mathrm{dL}$ \\
\hline PPBS & $237.9 \pm 66.2 \mathrm{mg} / \mathrm{dL}$ \\
\hline HbA1c & $7.5 \pm 0.9$ \\
\hline Triglycerides & $168.8 \pm 70.3 \mathrm{mg} / \mathrm{dL}$ \\
\hline LDL & $42.2 \pm 10.5 \mathrm{mg} / \mathrm{dL}$ \\
\hline HDL & Table 3. Biochemical Parameters Among Study Population \\
\hline $\begin{array}{c}\text { FBS= Fasting blood glucose, PPBS= Post prandial blood } \\
\text { glucose, LDL=low density lipoprotein, HDL= high density } \\
\text { lipoprotein }\end{array}$ \\
\hline
\end{tabular}




\begin{tabular}{|c|c|c|c|c|}
\hline \multirow{2}{*}{ Variable } & \multicolumn{2}{|c|}{ TMT } & \multirow[b]{2}{*}{ Total } & \multirow{2}{*}{$\begin{array}{l}\chi_{\text {value }}^{2} \\
\text { (p-value) }\end{array}$} \\
\hline & Positive n, (\%) & Negative $n,(\%)$ & & \\
\hline \multicolumn{5}{|c|}{ Age } \\
\hline$<60$ Years & $6(10.5 \%)$ & $51(89.5 \%)$ & 57 & \multirow{2}{*}{$\begin{array}{l}21.6541 \\
<0.001^{*}\end{array}$} \\
\hline$\geq 60$ Years & $10(66.7 \%)$ & $5(33.3 \%)$ & 15 & \\
\hline \multicolumn{5}{|c|}{ Gender } \\
\hline Male & $10(22.7 \%)$ & $34(77.3 \%)$ & 44 & \multirow{2}{*}{$\begin{array}{c}0.0167 \\
0.897184\end{array}$} \\
\hline Female & $6(21.4 \%)$ & $22(78.6 \%)$ & 28 & \\
\hline \multicolumn{5}{|c|}{ Family History of Diabetes } \\
\hline Present & 9 & 20 & 29 & \multirow{2}{*}{$\begin{array}{c}2.1817 \\
0.139661 \\
\end{array}$} \\
\hline Absent & 7 & 36 & 45 & \\
\hline \multicolumn{5}{|c|}{ BMI(Kg/M²) } \\
\hline$\leq 22.9$ & $4(12.9 \%)$ & $27(87.1 \%)$ & 31 & \multirow{2}{*}{$\begin{array}{c}2.7353 \\
0.098153\end{array}$} \\
\hline$\geq 23$ & $12(29.3 \%)$ & $29(70.7 \%)$ & 31 & \\
\hline \multicolumn{5}{|c|}{ Duration of Diabetes } \\
\hline$\leq 10$ Years & $6(12 \%)$ & $44(88 \%)$ & 50 & \multirow{2}{*}{$\begin{array}{c}9.893 \\
0.001659 *\end{array}$} \\
\hline$>10$ Years & $10(45.5 \%)$ & $12(54.5 \%)$ & 22 & \\
\hline \multicolumn{5}{|c|}{ Hypertension } \\
\hline Present & $7(36.9 \%)$ & $12(63.1 \%)$ & 19 & \multirow{2}{*}{$\begin{array}{c}3.1919 \\
0.074002\end{array}$} \\
\hline Absent & $9(17 \%)$ & $44(83 \%)$ & 53 & \\
\hline \multicolumn{5}{|c|}{ Treatment } \\
\hline Oral Drugs & $9(17.3 \%)$ & $43(82.7 \%)$ & 52 & \multirow{2}{*}{$\begin{array}{c}2.6159 \\
0.105795\end{array}$} \\
\hline Insulin and Oral Drugs & $7(35 \%)$ & $13(65 \%)$ & 20 & \\
\hline \multicolumn{5}{|c|}{ Autonomic Neuropathy } \\
\hline Present & $6(35.3 \%)$ & $11(64.7 \%)$ & 17 & \multirow{2}{*}{$\begin{array}{c}2.2002 \\
0.137997\end{array}$} \\
\hline Absent & $10(18.1 \%)$ & $45(81.9 \%)$ & 55 & \\
\hline \multicolumn{5}{|c|}{ Fasting Blood Sugar (FBS) mg/dl } \\
\hline$<126$ & $4(14.3 \%)$ & $24(85.7 \%)$ & 28 & \multirow{2}{*}{$\begin{array}{c}1.6698 \\
0.196291\end{array}$} \\
\hline$\geq 126$ & $12(22.3 \%)$ & $32(72.7 \%)$ & 44 & \\
\hline \multicolumn{5}{|c|}{ Post Prandial Blood Sugar (PPBS) (mg/dl) } \\
\hline$<200$ & $6(21.4 \%)$ & $22(78.6 \%)$ & 28 & \multirow{2}{*}{$\begin{array}{c}0.0167 \\
0.897184\end{array}$} \\
\hline$\geq 200$ & $10(22.7 \%)$ & $34(77.3 \%)$ & 44 & \\
\hline$\overline{\text { HbA1c }}$ & & & & \\
\hline$<7$ & $0(0 \%)$ & $22(100 \%)$ & $22(100 \%)$ & \\
\hline$\geq 7$ & $16(32.0 \%)$ & $34(68.0 \%)$ & $50(100 \%)$ & $0.0016^{*}$ \\
\hline & & riglycerides & & \\
\hline$<150$ & $7(17.5 \%)$ & $33(82.5 \%)$ & 40 & 1.1612 \\
\hline$\geq 150$ & $9(23.1 \%)$ & $23(71.9 \%)$ & 32 & 0.281225 \\
\hline & & ity Lipoprotein (I & & \\
\hline$<100$ & $6(20.7 \%)$ & $23(79.3 \%)$ & 29 & 0.066 \\
\hline$\geq 100$ & $10(23.3 \%)$ & $33(76.7 \%)$ & 43 & 0.797272 \\
\hline & & ensity Lipoprotei & & \\
\hline$\geq 40$ & $5(13.9 \%)$ & $31(86.1 \%)$ & 36 & 2.8929 \\
\hline$<40$ & $11(30.5 \%)$ & $25(69.5 \%)$ & 36 & 0.088973 \\
\hline Table 4 & iation of TMT PC & ith Different Ris & in The Stu & \\
\hline
\end{tabular}

\section{DISCUSSION}

In developed countries, the disease scenario has changed from predominantly communicable diseases to predominantly non-communicable diseases. This trend is being followed in developing countries as well. Coronary Artery Disease (CAD) is one of the leading causes of death. ${ }^{8}$ Diabetes is the major risk factor for the development of CAD. Cardiac events in diabetes are particularly dangerous as they often occur without any warning symptoms. Cardiovascular autonomic neuropathy is present in about $20 \%$ asymptomatic diabetic patients. ${ }^{9}$ Repeated episodes of silent myocardial ischemia may lead to formation of myocardial fibrosis which later can lead to left ventricular dysfunction, arrhythmias, and sudden cardiac death. Early identification of SMI can prevent these potentially fatal events. ${ }^{10}$

In the present study, 72 asymptomatic diabetes patients who presented to outpatient clinic or admitted in wards at PESIMSR were studied. The mean age of participants in the present study was $50.5 \pm 9.4$ years. Khanapure $\mathrm{SP} 11$ et al studied 82 asymptomatic diabetic patients in a semi urban setting and found that mean age of study population was $52.74 \pm 9.816$. Bates RE et al.12 did a community-based study done in Olmsted city, Minnesota over a period of 16 years. The mean age study subjects were 54.7 years. Similar results were seen by Swaminathan K et $\mathrm{al}^{13}(52.3 \pm 5.6)$ and Lavekar AS et $\mathrm{al}^{14}(53.56 \pm 7.41)$. This may reflect the health-seeking behaviour of study subjects after the age of 40 years. In the present study it was observed that the association of inducible ischemia by TMT increases with age more than 60 years ( $p$ value $<0.001$ ). A study done by Sharada $M$ et al ${ }^{15}$ revealed higher prevalence of inducible ischemia in with increasing age ( $p$ value 0.0032). Similar results were observed by Premalatha G et al. ${ }^{16}$

Duration of diabetes is an important determinant of diabetes-related complications. Usually these complications set-in 10-20 years after the onset of diabetes mellitus. Since 
there is no nationwide screening program for diabetes detection, it is not possible to correctly determine the duration of diabetes. Most of these complications usually do not produce any symptoms initially. In the present study, the mean duration of diabetes was higher (8.8 years) compared to that in other studies Khanapure SP et al. (5.2 years), Swaminathan et al. (6.9 years), Lavekar AS et al. (6.3 years). In the present study, the rate of TMT positivity was proportionate to the duration of diabetes. Out of 22 subjects with a duration of diabetes $>10$ years, ten had TMT positive $(45.5 \%)$ which is highly significant compared to those with duration $\leq 10$ years $(12 \%)$ with $p$ - value $<0.05$. This shows a significant association of duration of diabetes in the development of inducible ischemia. In a study by Kim MK et al17 the positive predictive value of TMT in predicting CAD by angiography was higher when the duration of diabetes was more than ten years and in elderly. Similarly, a positive association between duration of diabetes and SMI has been reported by Langer $\mathrm{A}$ et $\mathrm{al}^{18}$ and Sharada $\mathrm{M}$ et al. ${ }^{15}$

In the present study, the TMT positivity rates were higher among those subjects whose glycaemic control is not optimum as determined by HbA1c. In the present study mean value of $\mathrm{HbA} 1 \mathrm{c}$ is $7.5 \pm 0.99$. In patients with $\mathrm{HbA} 1 \mathrm{c}<7$, TMT was found to be negative in all subjects $(n=22,100 \%)$. Among patients with HbA1c > 7, TMT was positive in $32 \%$ of subjects. This was statistically highly significant ( $p$-value 0.0016). A strong association between poor glycaemic control and inducible ischaemia has been observed by Lavekar AS et al. The mean value of FBS in the present study is $141 \mathrm{mg} / \mathrm{dl}$, which is closer to mean observed in Khanapure SP et al. (131), lower than the mean observed by Swaminathan et al. (179) in their studies. The mean PPBS is $238 \mathrm{mg} / \mathrm{dl}$ which is closer to values observed in both studies Khanapure SP et al. (248), Swaminathan et al. (226). However, FBS and PPBS levels did not correlate with the TMT positivity rate in the present study as they are not good indicators of long-term glycaemic control. Similar results were obtained in a study by Sharada $M$ et al.

In the present study, the mean BMI of study subjects was $24.84 \mathrm{~kg} / \mathrm{m}^{2}$. Similarly, in the study involving the rural population of Maharashtra by Lavekar AS et al.14 the mean BMI of the subjects were $25.62 \mathrm{~kg} / \mathrm{m}^{2}$. However, in the study by Khanapure SP et al. involving an urban population of Karnataka the mean BMI of the subjects were $30.44 \mathrm{~kg} / \mathrm{m}^{2}$ which is higher compared to the present study. TMT positivity rate is seen to be in correlation, though statistically not significant with BMI in the present study as well as in other studies.

Dyslipidaemia is commonly seen in patients with type 2 DM. In this study, lipid profile (Triglycerides, LDL cholesterol, HDL cholesterol) of the study subjects were studied and none of the variables showed significant association for inducible ischemia. Lipid abnormalities were significantly associated with inducible ischaemia in studies by Sharada $\mathrm{M}$ et al ${ }^{15}$ and Gazzaruso et al. ${ }^{19}$ On the contrary studies done by Bacci $\mathrm{S}$ et $\mathrm{al}^{20}$ and DIAD study ${ }^{21}$ failed to show any correlation between lipid abnormalities and silent ischaemia.

Among the study subjects, positive stress test for inducible ischemia was seen in patients using insulin compared to those using only oral anti-diabetic drugs (OADD) ( $35 \%$ vs. $17.3 \%$ ). This relation was also observed in the study conducted by Khanapure SP et al. (45.8\% vs. $23.9 \%$ ). Hence it can be inferred that that in persons on insulin therapy the risk of SMI is high. This may be because, as the duration of diabetes increases, the residual beta cell function decreases further, resulting in an unresponsiveness to OADDs. Eventually these patients require insulin for glycaemic control. In spite of TMT being positive in subjects on insulin, this was statistically not significant.

The prevalence of inducible ischemia in asymptomatic diabetes patients in the present study was $22.2 \%$, which is in concordance to the studies done by Kumar A et al. $(23.6 \%)^{22}$ and Lavekar AS et al. (21.1\%).14 This shows a significant presence of silent myocardial ischemia even in asymptomatic patients. These patients would be missed if only ECG and ECHO were done for diagnosing myocardial ischemia. A few studies have shown higher prevalence of silent ischemia in asymptomatic type 2 DM patients. The difference in prevalence rates of silent ischemia may be due to various factors like degree of occlusion in coronary vessels and the number of coronary vessels involved. Although modalities such as coronary angiography, Pharmacological stress scintigraphy, Exercise myocardial perfusion scintigraphy detects myocardial ischemia better; it requires a sophisticated set up which may not be available at rural areas. TMT can be used as a screening tool for diagnosing SMI in asymptomatic diabetic patients.

\section{CONCLUSION}

The silent nature of CAD in many diabetes patients results in them not being diagnosed for long periods of time. Hence there is a need for screening of diabetes patients for MI. The prevalence of inducible ischemia in asymptomatic diabetes patients in the present study is $22.2 \%$. This study shows that TMT is useful in the early detection of SMI. In a rural setup where there are limited resources, TMT can be used as a screening tool for diagnosing SMI. Elderly diabetics with longer duration of diabetes and poor glycaemic control had higher prevalence of inducible ischemia. Good glycaemic control had a protective effect against development of CAD.

\section{Limitations of the Study}

Purposive sampling was used in the study which may not be an actual representation of general population. Large-scale randomised control trials are recommended to assess the prevalence of silent myocardial ischemia in DM patients which helps in initiating appropriate treatment early.

\section{REFERENCES}

[1] Misra A, Vikram NK. Insulin - resistance syndrome (metabolic syndrome) and Asian Indians. Current Sci 2002;83(12):1483-96.

[2] Mathers CD, Loncar D. Projections of global mortality and burden of disease from 2002 to 2030. PLoS Med 2006;3(11):e442.

[3] Ali MK, Narayan KMV, Tandon N. Diabetes and Coronary heart disease: current perspectives. Indian J Med Res 2010;132(5):584-97.

[4] Joshi AS, Lahane CG, Kashid AA. The result of treadmill test in asymptomatic type 2 diabetes mellitus. Int J Sci Rep 2017;3(6):166-72.

[5] Koistinen MJ. Prevalence of asymptomatic myocardial ischemia in diabetic subjects. BMJ 1990;301(6743):92-5. 
[6] Consensus development conference on the diagnosis of Coronary Heart Disease in people with diabetes: 1011 February 1998, Miami, Florida. American Diabetes Association. Diabetes Care 1998;21(9):1551-9.

[7] Luong MW, Ignaszewski M, Taylor CM. Stress testing: a contribution From Dr. Robert A. Bruce, father of exercise cardiology. BCMJ 2016;58(2):70-6.

[8] Upadhyay RP. An overview of the burden of noncommunicable diseases in India. Iran J Public Health 2012;41(3):1-8.

[9] Ziegler D, Gries FA, Spuler M, et al. The epidemiology of diabetic neuropathy. Diabetic Cardiovascular Autonomic Neuropathy Multicenter Study Group. Journal of Diabetes and its Complications 1992;6(1):49-57.

[10] Boras J, Brkljacic N, Ljubicic A, et al. Silent ischemia and diabetes mellitus. Diabetologia Croatica 2010;39(2):57-65.

[11] Khanapure SP, Parmar D, Bajaj G, et al. Prevalence of Silent Coronary Artery Disease (CAD) in asymptomatic T2DM - a prospective study. International Journal of Contemporary Medical Research 2017;4(11):2341-5.

[12] Bates RE, Omer M, Abdelmoneim SS, et al. Impact of stress testing for coronary artery disease screening in asymptomatic patients with diabetes mellitus: a community-based study in Olmsted County, Minnesota. Mayo Clin Proc 2016;91(11):1535-44.

[13] Swaminathan K, Gayathri M. Study of treadmill test in detecting asymptomatic Coronary Artery Disease in type 2 diabetes mellitus. IOSR Journal of Dental and Medical Sciences (IOSR-JDMS) 2016;15(8):1-6.

[14] Lavekar AS, Salkar HR. Treadmill test to detect stress induced ischemic heart disease in type 2 diabetes mellitus patients asymptomatic for CAD: a hospitalbased cross-sectional study in rural population of Central India. J Diabetes Metab 2013;4(2):244.
[15] Sharda M, Soni AK, Meena S, et al. Prospective study on the utility of exercise treadmill test in type 2 diabetes mellitus patients. Journal of Association of Physicians of India 2016;64(11):32-7.

[16] Premalatha G, Anirudhan MK, Mohan V, et al. Treadmill (Cardiac Stress) test in the diagnosis of ischaemic heart disease in NIDDM patients: usefulness and safety. Int J Diab Dev Countries 1995;15:3-6.

[17] Kim MK, Baek KH, Song KH, et al. Exercise treadmill test in detecting asymptomatic coronary artery disease in type 2 diabetes mellitus. Diabetes Metab J 2011;35(1):34-40.

[18] Langer A, Freeman MR, Josse RG, et al. Detection of Silent myocardial ischemia in diabetes mellitus. Am J of Cardiol 1991;67(13):1073-8.

[19] Gazzaruso C, Garzaniti A, Giordanetti S, et al. Silent coronary artery disease in type 2 diabetes mellitus: the role of Lipoprotein (a), homocysteine and apo (a) polymorphism. Cardiovascular Diabetology 2002;1:5.

[20] Bacci S, Villella M, Villella A, et al. Screening of silent myocardial ischemia in type 2 diabetic patients with additional atherogenic risk factors: applicability and accuracy of the exercise stress test. Eur J Endocrinol 2002;147(5):649-54.

[21] Wackers FJ, Young LH, Inzucchi SE, et al. Detection of silent myocardial ischemia in asymptomatic diabetic subjects: the DIAD study. Diabetes care 2004;27(8):1954-61.

[22] Kumar A, Singh VK. Screening for silent myocardial ischemia by application of exercise stress test: an observational cross-sectional study. Int J Sci Stud 2014;2(6):91-5. 